\title{
Bilateral coronary artery fistula as a cause of angina pectoris
}

\author{
Shi-Wei Yang, ${ }^{1,2}$ Yu-Jie Zhou, ${ }^{1,2}$ Da-Yi Hu ${ }^{3}$
}

'Department of Cardiology, Beijing An Zhen Hospital, Capital Medical University; Beijing Institute of Heart Lung and Blood Vessel Disease, Beijing, China

${ }^{2}$ The Key Laboratory of Remodeling-related Cardiovascular Disease, Ministry of Education, Beijing, China

${ }^{3}$ Department of Cardiology, Peking University People's Hospital, Beijing, China

\section{Correspondence to} Professor Yu-Jie Zhou, jackydang@163.com
To cite: Yang S-W,

Zhou Y-J, Hu D-Y. BMJ Case Rep Published online:

[please include Day Month Year] doi:10.1136/bcr-2013008971

\section{DESCRIPTION}

A 75-year-old female patient was admitted to our hospital presenting with episodes of exhausted chest pain for 2 years. A continuous murmur was heard over the precordium. The repeated ECG and echocardiograms were normal. At cardiac catheterisation, a left-to-right shunt of 1.33:1 (Qp: Qs) was found. Coronary angiography showed one fistula arising in left anterior descending artery ending in the left atrium (figure 1A-D), and a second fistula arising in right coronary artery and terminating in the pulmonary artery (figure $1 \mathrm{E}, \mathrm{F}$ ). Multislice CT angiography (figure 2) showed the left and right fistulas entering the left atrium and the pulmonary artery, respectively. The patient was referred for surgical ligation of the fistulas. After 2 weeks the patient was discharged and she has shown symptom-free at follow-ups. Generally, most coronary artery fistulas (CAFs) manifest as a single fistula and drain into one of the cardiac chambers; cases of multiple fistulas are rare. According to the site of drainage, CAFs have varied physiological presentations. ${ }^{1}$ A fistula that drains into the left atrium does not result in a left-to-right shunt, but rather causes a volume load

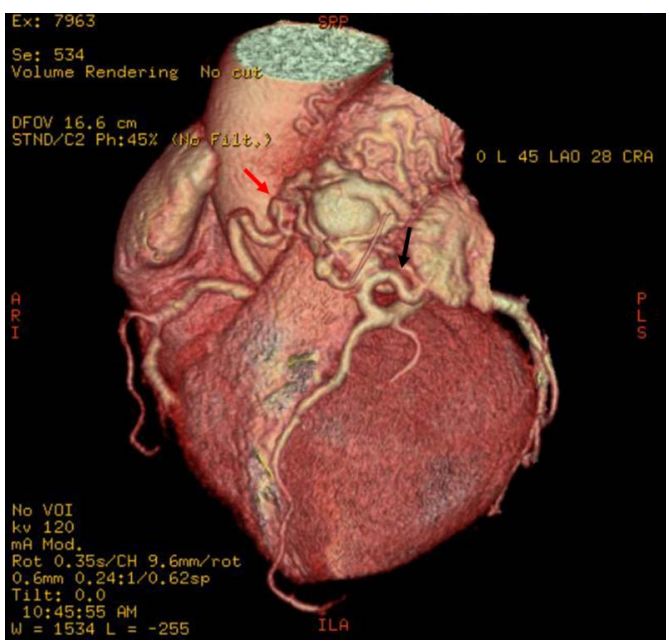

Figure 2 Multislice CT angiography showed the left (black arrow) and right fistulas (red arrow) entering the left atrium and the pulmonary artery, respectively.

similar to mitral regurgitation. The CAFs that drain into the pulmonary arteries are similar haemodynamically to a patent ductus arteriosus.

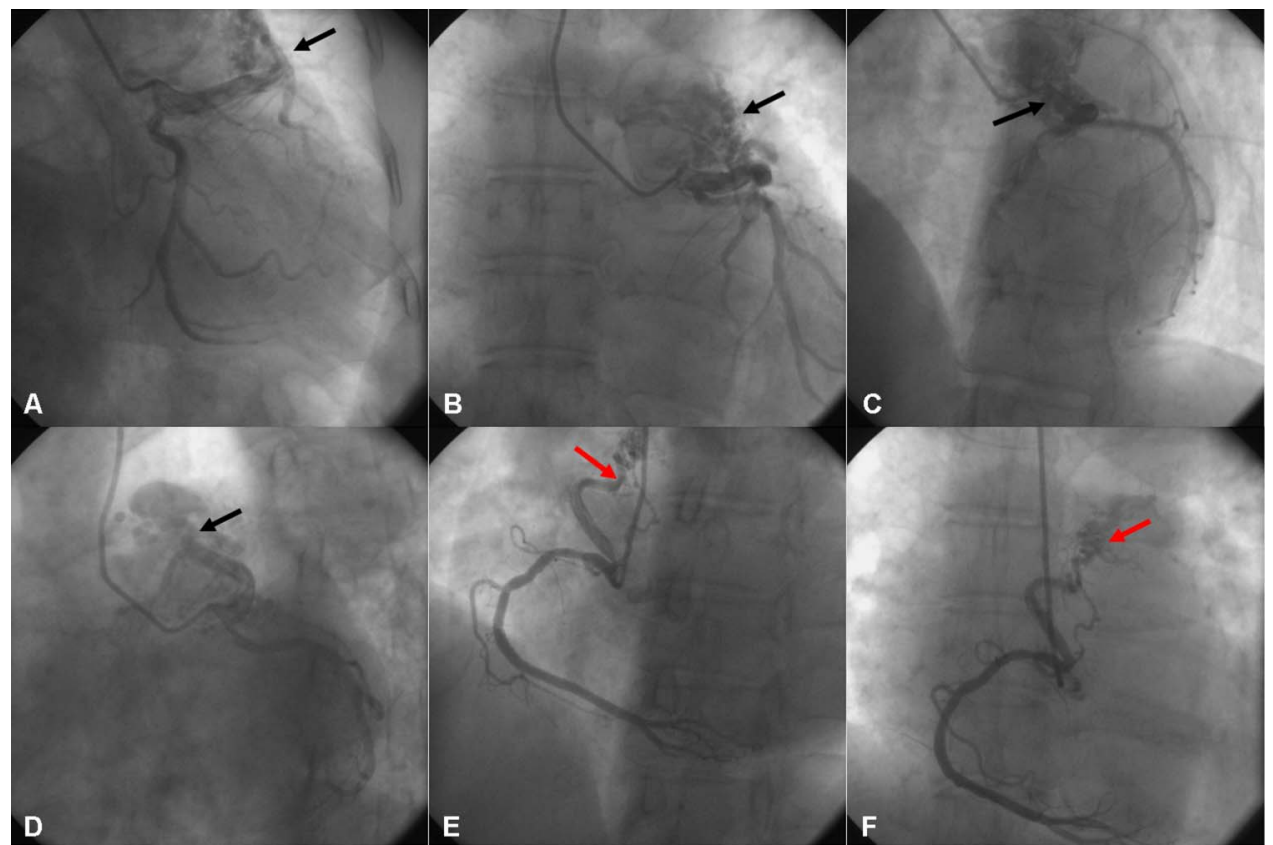

Figure 1 Coronary angiography showed one fistula (black arrow) arising in left anterior descending artery ending in the left atrium (A-D), and a second fistula (red arrow) arising in right coronary artery and terminating in the pulmonary artery (E and $\mathrm{F})$. 


\section{Learning point}

Most coronary artery fistulas (CAFs) are often clinically silent and inconsequential. However, bilateral CAFs may have a clinical and embryological significance on the basis of coronary steal phenomenon. ${ }^{2}$ There appears to be good consensus that all symptomatic patients should undergo closure of medium or large CAFs.
Competing interests None.

Patient consent Obtained.

Provenance and peer review Not commissioned; externally peer reviewed.

\section{REFERENCES}

1 Latson LA. Coronary artery fistulas: how to manage them. Catheter Cardiovasc Interv 2007;70:110-16.

2 Vijayvergiya $\mathrm{R}$, Bhadauria PS, Jeevan $\mathrm{H}$, et al. Myocardial ischemia secondary to dual coronary artery fistulas draining into main pulmonary artery. Int I Cardiol 2010;140: e30-3.

Copyright 2013 BMJ Publishing Group. All rights reserved. For permission to reuse any of this content visit http://group.bmj.com/group/rights-licensing/permissions.

BMJ Case Report Fellows may re-use this article for personal use and teaching without any further permission.

Become a Fellow of BMJ Case Reports today and you can:

- Submit as many cases as you like

- Enjoy fast sympathetic peer review and rapid publication of accepted articles

- Access all the published articles

- Re-use any of the published material for personal use and teaching without further permission

For information on Institutional Fellowships contact consortiasales@bmjgroup.com

Visit casereports.bmj.com for more articles like this and to become a Fellow 